\title{
DISTRIBUIÇÃO DE RENDA, CRESCIMENTO ECONÔMICO E MUDANÇA ESTRUTURAL NA TRADIÇÃO DO ESTRUTURALISMO LATINO- AMERICANO: UMA SISTEMATIZAÇÃO EM QUATRO MOMENTOS
}

\author{
Rodrigo Vergnhanini ${ }^{a}$ \\ André Martins Biancarelli ${ }^{b}$ \\ aProfessor Adjunto do Instituto de Economia da Universidade Federal do Rio de Janeiro (UFRJ). Rio de \\ Janeiro, RJ, Brasil. ORCID: https://orcid.org/0000-0001-5609-6222.

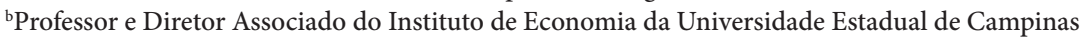 \\ (UNICAMP). Campinas, SP, Brasil. ORCID: https://orcid.org/0000-0002-2224-3607.
}

RESUMO: O artigo investiga contribuições da literatura estruturalista latino-americana com relação às dinâmicas internas entre crescimento, mudança estrutural e distribuição de renda. A partir da análise da literatura primária e secundária, reúne as contribuições em quatro importantes "momentos": (i) "insuficiência dinâmica"; (ii) "estilos de desenvolvimento"; (iii) "transformação produtiva com equidade"; e (iv) "abordagem integrada". Em termos conclusivos, o artigo destaca três lições para a análise do desenvolvimento hoje: do ponto de vista teórico, a suposição de relativa autonomia entre os determinantes do crescimento, distribuição de renda e estrutura produtiva; do ponto de vista analítico, a importância da consideração conjunta dessas dimensões num corpo analítico amplo, que seja capaz de considerar diferentes possibilidades ou "estilos" de desenvolvimento econômico; e, do ponto de vista normativo, 
a defesa de "estilos" que sejam socialmente desejáveis e que possam orientar a atuação das políticas econômicas.

PALAVRAS-CHAVE: desenvolvimento; Estruturalismo; CEPAL; distribuição de renda; crescimento.

CLASSIFICAÇÃO JEL: $O 1$. 


\title{
INCOME DISTRIBUTION, GROWTH AND STRUCTURAL CHANGE IN THE TRADITION OF LATIN-AMERICAN STRUCTURALISM: A SYSTEMATIZATION
}

\begin{abstract}
This article explores the contributions of Latin-American structuralist literature in relation to the internal dynamics between income distribution, growth, and structural change. Relying on primary and secondary literature, it organizes the main contributions in four groups: (i) "insufficient dynamics"; (ii) "styles of development"; (iii) "structural change with social equity"; and (iv) "integrated approach". It concludes by selecting three main lessons for the current development thinking: the theoretical assumption of relative autonomy between the determinants of income distribution, growth, and structural change; the consideration of a broad analytical framework, which could be useful to indicate different development "styles"; and finally the defense of certain development "styles" that are socially desirable and that could guide the economic policies.
\end{abstract}

KEYWORDS: development; Structuralism; ECLAC; income distribution; growth. 


\section{INTRODUÇÃO}

Diante da experiência recente de diversos países latino-americanos, que de forma inédita combinaram crescimento acelerado e distribuição de renda, e dos desafios que este processo passou a enfrentar ao longo da primeira metade dos anos 2010, ressurgiu no debate acadêmico um tema clássico na literatura estruturalista sobre desenvolvimento: os vínculos e as causalidades entre a distribuição de renda, o crescimento econômico e a estrutura produtiva. Neste contexto, e a propósito da comemoração dos 70 anos do "manifesto estruturalista" de Prebisch, o presente artigo pretende visitar, de maneira panorâmica, a literatura heterodoxa do desenvolvimento - especialmente a produção oriunda ou vinculada à Comissão Econômica para a América Latina e o Caribe (CEPAL) nessas sete décadas de existência - que envolve a articulação entre aquelas dimensões.

Apoiando-se nos trabalhos originais dos grandes mestres dessa tradição e também em sínteses posteriores, a contribuição específica deste artigo é, a partir do referido recorte, fazer uma sistematização dos principais "momentos" da literatura estruturalista latino-americana, na qual se destacarão as abordagens mais recentes da CEPAL. Sublinhe-se, desde logo, que não se trata de uma exegese da literatura cepalina, mas de um olhar necessariamente seletivo em termos temáticos. Particularmente, dois elementos centrais dessa tradição não são aprofundados: a restrição externa e as relações entre o comércio exterior e o desenvolvimento.

O artigo está estruturado em cinco seções além desta introdução, referentes aos quatro momentos da teoria heterodoxa do desenvolvimento latino-americano, aqui denominados: (i) "insuficiência dinâmica"; (ii) "estilos de desenvolvimento"; (iii) "transformação produtiva com equidade"; e (iv) "abordagem integrada: crescer para igualar e igualar para crescer”. A quinta seção sintetiza as principais lições dessa literatura para a discussão sobre o desenvolvimento econômico no tempo atual.

Optou-se por apresentar cada um desses momentos a partir da configuração histórica em que surgiu e da problemática que se destinou a tratar. A preocupação com a contextualização de cada controvérsia teórica segue o próprio método do estruturalismo cepalino, que parte da materialidade histórica e concreta para avançar na teorização específica e particular dos fenômenos. ${ }^{1}$

\footnotetext{
1 O método histórico-estrutural consiste no tratamento das estruturas econômicas de determinadas realidades, e cuja transformação se produz no tempo, historicamente (RODRIGUEZ, 2009, p. 46). Para Bielschowsky (2000, p. 23), trata-se de um método atento ao comportamento dos agentes sociais e à trajetória das instituições, que tem maior proximidade a um movimento indutivo do que os enfoques abstrato-dedutivos tradicionais residindo numa fértil interação entre o método indutivo e a abstração teórica e analítica formulada originalmente por Prebisch.
} 


\section{DA ESCASSEZ DE POUPANÇA À TENDÊNCIA ESTRUTURAL À ESTAGNAÇÃO: AS TESES DA "INSUFICIÊNCIA DINÂMICA" (ANOS 1960)}

A teoria do desenvolvimento, nascida nos anos 1940, herda o "paradigma clássico" ou "ricardiano", segundo o qual a parcela dos lucros era dada exogenamente pela tecnologia e por um salário real dado pelo custo de reprodução social da força de trabalho. $\mathrm{O}$ produto efetivo seria determinado pelo produto potencial já existente e a poupança (potencial) determinaria diretamente o investimento, em clara adesão às relações causais estabelecidas pela Lei de Say. Portanto, dados os lucros potenciais, o investimento seria aquilo que sobrasse do consumo (ou qualquer gasto improdutivo) (SERRANO, 2001, p. 140).

Importante peça dessa tradição, o trabalho seminal de Lewis (1954) apontava para a inadequação da teoria neoclássica, baseada no princípio da escassez, para o tratamento de economias atrasadas com “oferta ilimitada de mão de obra”. Segundo Lewis, essas economias seriam marcadas por uma peculiaridade, em relação às desenvolvidas: a dualidade entre setor de subsistência e setor moderno capitalista. Dado que os salários se aproximam do nível de subsistência, o setor moderno, que goza de maior produtividade do trabalho, gera um montante ampliado de lucros e, consequentemente, de poupança potencial. Essa poupança, convertida em investimento, seria capaz de acelerar o crescimento econômico, transferindo cada vez mais trabalhadores do setor de subsistência para o capitalista, o qual teria incentivos para empregar mão de obra até o ponto em que o salário real se tornasse igual à produtividade marginal.

Portanto, partindo de um arsenal "clássico" baseado na consideração dos salários no nível de subsistência e da determinação da renda pela poupança, o modelo de Lewis conclui que a acumulação acelerada, fruto da maior apropriação do excedente pela classe capitalista, tenderia a eliminar o excedente estrutural de mão de obra e, portanto, o próprio mercado dual de trabalho.

Assim, a teoria do desenvolvimento se apresenta como uma crítica à ortodoxia neoclássica, um "caso particular" teórico respondendo a condições históricoempíricas específicas cuja validade se encerra na medida em que essas peculiaridades são eliminadas pelo próprio desenvolvimento econômico. (BASTOS e D’AVILA, 2009, p. 178)

O Estruturalismo latino-americano, que se origina do relatório de Raúl Prebisch para a CEPAL em 1949, herda dessa abordagem sua estrutura lógica geral. Porém, o pensamento cepalino nega, desde seus documentos iniciais, o otimismo de Lewis. A absorção do excesso de mão de obra no setor moderno é mitigada pela possibilidade 
de o excedente gerado pelo setor capitalista não se tornar poupança-investimento, mas se orientar ao consumo conspícuo das minorias de renda mais alta. A "escassez de poupança” (junto com a dependência tecnológica, que será explorada mais adiante) tenderia a gerar "insuficiência dinâmica" (PREBISCH, 2000[1963]).

Essas hipóteses se alimentaram da inquietação gerada pela persistência empírica do subemprego mesmo com o logro de uma acelerada industrialização nos anos 1950. Diferentemente do esperado a partir da racionalização de Lewis e de outros modelos oriundos de países desenvolvidos, a migração da população de áreas rurais para as urbanas não ocorreu via absorção por atividades no setor moderno, mas sim elevou desemprego disfarçado e a marginalização. Ou seja, crescia a evidência de nova modalidade de pobreza e desequilíbrio social (crescentemente urbano) simultaneamente à modernização promovida pelo processo de industrialização (BASTOS e D’ÁVILA, 2009, p. 182-183).

Ademais, a desaceleração do crescimento em vários países da América Latina no início dos anos 1960 gerou a percepção de que o modelo anterior havia chegado a estrangulamentos e desequilíbrios econômicos, setoriais e sociais. Portanto, os pensadores cepalinos se inclinaram a discutir quais seriam os limites estruturais do crescimento econômico naquele modelo e as reformas necessárias para sua desobstrução.

Dois tópicos centrais foram desenvolvidos nesse contexto. Em primeiro lugar, produziu-se uma teorização particular do caráter excludente do processo de industrialização que se firmava na região. A partir dos conceitos de heterogeneidade estrutural e de subdesenvolvimento, as análises fundamentaram certo pessimismo sobre as possibilidades de superação do atraso e da absorção do excedente de mão de obra. A segunda ideia, explorada por alguns importantes autores, era de que esse modelo de industrialização, precisamente por ser excludente, estava fadado à estagnação.

Com relação ao primeiro tema, destaca-se a "teoria do subdesenvolvimento" de Celso Furtado (1963, p. 180). O autor rompe com a leitura linear rostowiana do desenvolvimento, em que este seria composto por etapas paulatinas em direção à eliminação da dualidade estrutural. Em contraste, o subdesenvolvimento seria uma estrutura estável, um processo histórico autônomo e fruto do padrão de desenvolvimento adotado no Brasil desde a década anterior (BASTOS e D’ÁVILA, 2009, p. 181-182). Sua hipótese central é que o crescimento e a industrialização seriam incapazes de eliminar a dualidade básica da economia, não absorvendo o excedente estrutural de mão de obra no setor moderno e de alta produtividade.

De forma paralela, Aníbal Pinto (1970) constatava que os frutos do progresso técnico tendiam a se concentrar, tanto no que se refere à distribuição entre classes, quanto no que diz respeito à distribuição entre setores e entre regiões de um país. Formulava assim sua tese da "heterogeneidade estrutural". 
Partindo dessa análise, alguns autores avançaram uma hipótese mais forte: a de que o modelo de desenvolvimento vigente levaria as economias inexoravelmente à estagnação. É preciso entender como essa hipótese, em particular, se articula com os modelos teóricos dos autores.

Um primeiro mecanismo explicativo da hipótese estagnacionista pode ser identificado na ideia de escassez de poupança, que remete às teorias originais da CEPAL, tanto nas obras de Prebisch quanto nas de Furtado. Como argumentado, dentro do "paradigma clássico", o "consumo de luxo" diminui a parcela do excedente destinado a se tornar poupança-investimento e contribui para desacelerar o crescimento econômico. Esse consumo resultaria da emulação, por parte das elites, dos padrões culturais dos países avançados.

Desde os anos 1950, Prebisch atribuía tanto à insuficiência de poupança quanto à utilização de tecnologias intensivas em capital a responsabilidade pela incapacidade de absorver a força de trabalho. Para ele, seria necessário restringir o consumo das classes ricas em favor do investimento e do progresso técnico. Nos anos 1960, Prebisch (2000[1963]) desdobra o raciocínio para a questão agrária. Os latifundiários rentistas entorpecem a produtividade agrícola, pois dão mau uso ao excedente. Portanto, a reforma agrária é condição para aumentar a produtividade agrícola e melhorar o uso social do excedente potencial (apud BIELSCHOWSKY, 2000, p. 39-40).

Em Furtado (1966), a tendência à estagnação difere da "insuficiência dinâmica" de Prebisch. Enquanto este trata da disponibilização de poupança potencial para o investimento produtivo, o brasileiro analisa e caracteriza os componentes da demanda para indagar se sua evolução (e as pautas distributivas que a condicionam) é ou não adequada para a continuidade do crescimento periférico ou se culminam na sua paralisação (RODRÍGUEZ, 2009, p. 315). Daí, segundo Bielschowsky (2000, p. 40), deriva a tese furtadiana de "insuficiência dinâmica da demanda".

Se, no centro, a difusão de bens de consumo é elemento chave do crescimento econômico, na periferia isso não ocorre precisamente devido à superabundância da força de trabalho, que inibe o aumento dos salários e a melhora na distribuição de renda. Portanto, a expansão do setor de bens de consumo na periferia restringe-se à satisfação das necessidades de consumo de artigos de elevado valor unitário pelos estratos mais altos da sociedade e, sendo esse grupo minoritário, o seu potencial de transformação da estrutura produtiva tende a ser bastante limitado (RODRÍGUEZ, 2009, p. 332). Ainda que se considerasse a criação de novas necessidades de bens de consumo conspícuo, de forma que a demanda por eles se renovasse continuamente, haveria outros entraves à ampliação da oferta, relacionados às características das tecnologias geradas nos centros, que, quando transplantadas para a periferia, causariam ineficiência da produção e desestímulos ao investimento (RODRÍGUEZ, 2009, p. 332). 
O progresso técnico no centro é fruto de um processo histórico de aumento progressivo na quantidade de capital por unidade de trabalho, isto é, um aumento na densidade de capital, que refletiria a evolução da dotação dos fatores de produção naqueles países. Os sucessivos incrementos na densidade do capital seriam acompanhados por uma diminuição da sua produtividade, ou seja, queda da relação produto/capital. O processo de modernização da periferia, por outro lado, teria ocorrido com a utilização de uma tecnologia “inadequada”, importada dos países centrais, em condições de dotação de recursos totalmente distintas; seu emprego, portanto, envolveria a sobreutilização do recurso escasso, capital, em detrimento do recurso abundante, trabalho.

Um segundo pressuposto concerne às elevadas escalas mínimas de produção, que também contribuem para aumentar a quantidade de capital necessária por produto.

Em conformidade com essa tese de Furtado, Maria da Conceição Tavares (1972) afirma que, na segunda fase do processo de industrialização por substituição de importações, quando se avança para etapas que exigem maiores escalas e são de mais alta complexidade tecnológica (elevada relação capital/produto), surgem problemas relacionados ao montante de capital necessário e à dimensão do mercado que podem frear a diversificação industrial. Nos setores em que a substituição ainda é possível, essa alta intensidade de capital da produção gera rendimentos macroeconômicos decrescentes. Portanto, assim como Furtado, a autora concluía que a tendência à estagnação econômica tinha determinantes estruturais, sendo estritamente necessárias mudanças no modelo de desenvolvimento (BIELSCHOWSKY, 2011, p. 227).

Furtado (1963) descreve essas relações indicando os nexos de "causação circular", num modelo em que os padrões de oferta e demanda se reforçam para gerar uma dinâmica de desaceleração do crescimento econômico. Em outras palavras, o dualismo do mercado de trabalho garantiu que a acumulação de capital fosse acompanhada de crescente desigualdade e aprofundamento do dualismo no mercado de consumo. Este, por sua vez, fazia com que se avançasse para segmentos de maior intensidade tecnológica, gerando crescente ineficiência na produção, desincentivo ao investimento e tendência à estagnação.

Com base nesses argumentos, os defensores da tese estagnacionista buscaram destacar a inviabilidade econômica do modelo de desenvolvimento e de industrialização vigente. Reformas estruturais seriam imprescindíveis para desobstruir a industrialização e dinamizar a economia, em médio e longo prazos. Somente a reforma agrária, e seus efeitos benéficos sobre emprego e distribuição de renda, permitiria ampliar a base de consumo para produtos industriais menos exigentes em termos de capital e escala, e induzir uma recomposição nos investimentos industriais. 


\section{CRÍTICAS À TESE ESTAGNACIONISTA E OS “ESTILOS DE DESENVOLVIMENTO” (ANOS 1970)}

No Brasil, após o arrefecimento das taxas de crescimento entre 1962 e 1967, seguiu-se uma forte aceleração no ritmo de expansão da economia, no que se convencionou chamar de "milagre brasileiro". Em paralelo, a América Latina também desfrutava de crescimento acelerado ao longo da década de 1970. Diante disso, a literatura estruturalista se deparou com a necessidade de revisar a tese estagnacionista e explicar as origens desse grande dinamismo - já que este se firmava nas economias latino-americanas ainda que as marcas definidoras do subdesenvolvimento (heterogeneidade estrutural e concentração de renda) não tivessem sido enfrentadas.

Nesse contexto, e voltando-se ao caso particular da economia brasileira, Tavares e Serra (1972) substituem o problema da estagnação pelo problema do padrão de acumulação para o qual se transitava naquele contexto histórico. Para eles, a desaceleração observada no início dos anos 1960 não era o início de um estancamento secular, mas uma crise relacionada com as dificuldades emergentes do processo de substituição de importações e transição para um "novo estilo" de desenvolvimento (RODRÍGUEZ, 2009, p. 338). Sua análise remete assim ao paradigma teórico dos “estilos", discutido mais adiante nesta seção.

Os autores concordam com Furtado no sentido de que a estrutura de demanda concentrada e a estrutura de oferta intensiva em capital se alimentam mutuamente, promovendo concentração de renda e agravamento da heterogeneidade estrutural. No entanto, discordam daquele autor ao afirmar que a concentração não é contraditória com as condições determinantes do dinamismo econômico.

Tavares e Serra questionam, particularmente, a ideia de que a razão crescente entre capital e produto, descrita por Furtado, implicaria necessariamente um excedente menor disponível para reinvestimento nas economias subdesenvolvidas. Eles mostraram que o argumento estagnacionista dependia da suposição bastante forte de que não há ganhos de produtividade do trabalho ao longo do processo de industrialização. Uma maior produtividade do trabalho poderia, por um lado, compensar a maior densidade de capital (e anular a variação da produtividade do capital) e, por outro, determinar uma maior participação dos lucros na renda (compensando a eventual elevação da relação capital/produto sobre a taxa de lucros). ${ }^{2}$ Em suma, ao se considerar os ganhos da produtividade do trabalho, pode-se afirmar que não necessariamente o aumento da densidade do capital irá desfavorecer as condições de lucratividade necessárias para a continuidade da acumulação.

2 Ver a respeito Bastos e D’Ávila (2009) e Rugitsky (2016). 
Além disso, Tavares e Serra argumentaram que a desaceleração observada no início dos anos 1960 não seria sintoma de uma tendência secular à estagnação, mas de uma crise cíclica decorrente de insuficiência de demanda, assim como da ociosidade na indústria herdada do boom de investimentos do Plano de Metas. Esses problemas, que prejudicavam o crescimento, foram superados com a política econômica de concentração de renda e as reformas promovidas pelo governo militar, sobretudo do setor financeiro que permitiu o financiamento do consumo de bens duráveis e da construção civil.

Ou seja, apesar de todas as fontes do atraso e da concentração da renda, a massificação do consumo de bens industriais tornava-se compatível com qualquer tipo de mercado de trabalho. As famílias, beneficiadas por crédito barato, tiveram amplo acesso aos bens de consumo duráveis (por exemplo, a televisão). Essa rápida expansão dos padrões modernos ocorreu, contudo, de forma muito desigual e num contexto de carências de todo tipo, incluindo as de transporte, saúde, educação e habitação (MEDEIROS, 2001, p. 180). Nesse cenário, ficava cada vez mais aparente o equívoco em se atribuir à concentração da renda uma tendência à estagnação.

Do ponto de vista teórico, pode-se dizer que a análise de Tavares e Serra se baseou em um instrumental keynesiano/kaleckiano, ou de demanda efetiva, segundo o qual a trajetória do crescimento deve ser explicada pelo comportamento das variáveis de demanda e não pela poupança. Representou, assim, a superação do fundamento clássico da teoria do investimento (segundo o qual há uma relação direta entre concentração de renda e maior acumulação). Por outro lado, ao se contrapor à tese estagnacionista, reconheceu que o crescimento econômico não depende intrinsecamente da distribuição de renda, mas pode ser puxado pela demanda autônoma. Ou seja, nas suas análises “(...) a relação entre concentração de renda e crescimento não mais se determina de forma direta e unívoca" (BASTOS e D’ÁVILA, 2009, p. 185).

No que diz respeito à esquematização do pensamento estruturalista latino-americano aqui proposta, as críticas ao estagnacionismo lideradas por Tavares e Serra podem ser compreendidas dentro um escopo analítico mais amplo que se desenvolveu no âmbito da CEPAL nos anos 1970. Os autores foram discípulos de Aníbal Pinto que, além de formulador da tese sobre a heterogeneidade estrutural (PINTO, 1970), viria a escrever uma importante referência da linha interpretativa de "estilos de desenvolvimento" (PINTO, 2000[1976]). O autor utiliza a definição do sociólogo cepalino Jorge Graciarena de que "estilos são a 'modalidade concreta e dinâmica adotada por um sistema num momento histórico determinado"' (PINTO, 2000[1976], p. 617). E complementa dizendo que

visto por um ângulo estritamente econômico, poderíamos entender por estilo de desenvolvimento a maneira como, dentro de um determinado sistema, os recursos 
humanos e materiais são organizados e distribuídos, com o objetivo de resolver as indagações sobre o que, para quem e como produzir os bens e serviços. (PINTO, $2000[1976]$, p. 619)

Os "estilos" ou modalidades de desenvolvimento têm sua dinâmica nas interações entre a estrutura de demanda (distribuição de renda, o "para quem") e da oferta (acumulação de capital e progresso técnico, o "o quê"). Trata-se, portanto, de fértil integração de elementos centrais da análise cepalina das décadas anteriores. Diferencia-se, porém, de parte da produção estruturalista do período, sobretudo daquela dedicada à tese estagnacionista, na medida em que não propõe limites ao crescimento, mas insinua a possibilidade de que se apresentem dinâmicas diferenciadas, correspondendo a padrões distributivos diferentes (RODRÍGUEZ, 2009, p. 313).

Em relação às "dimensões econômicas” de cada estilo, Pinto destaca, por um lado, os "fatores estruturais" ou "estáticos" e, por outro, os "fatores dinâmicos". Os primeiros envolvem a estrutura produtiva e a ocupacional, marcadas pela heterogeneidade estrutural (coexistência de níveis de produtividade do trabalho muito diferenciados). Os fatores dinâmicos, por sua vez, consistem no nível e na composição da demanda por bens e serviços, sendo esta última influenciada pela distribuição da renda.

Cada "estilo de desenvolvimento" é caracterizado pela combinação entre certa "base estrutural" e certos "fatores dinâmicos", determinados em instâncias próprias, ainda que estejam, contudo, interrelacionados. Pinto incorpora, então, o critério ético/ normativo ao afirmar que, dentre os vários estilos de crescimento possíveis, nem todos são desejáveis. É preciso avaliar "se a orientação da parte mais vital da estrutura produtiva (...) é compatível com o atendimento das necessidades ou consumos da grande maioria e com outros objetivos do desenvolvimento (...) [entre eles] (...) a aceleração da sua marcha” (PINTO, 2000[1976], p. 125).

Voltando-se à realidade da América Latina em meados dos anos 1970, Pinto lamenta o "círculo de causalidade negativa" do estilo vigente em alguns países da região, em que a concentração de renda alimenta a estrutura produtiva e vice-versa, perpetuando a desigualdade e impedindo o enfrentamento da pobreza. A continuidade desse estilo de desenvolvimento implica excluir segmentos amplos da população. Ainda que sustente a dinâmica econômica da estrutura de oferta internalizada nessas economias, esse caminho "não é aceito em termos dos valores professados pela comunidade internacional" (PINTO, 2000[1976], p. 635).

Insere, assim, na avaliação de qualquer modelo vigente, não apenas um julgamento sobre sua viabilidade econômica, mas também questionamento dos seus aspectos éticos, principalmente o critério de justiça distributiva. Caberia à ação estatal se dedicar à reorientação do estilo de desenvolvimento na direção da homogeneidade social. 


\section{O NEOESTRUTURALISMO E A "TRANSFORMAÇÃO PRODUTIVA COM EQUIDADE" (ANOS 1990)}

O contexto da década de 1980 impôs uma inflexão no objeto principal das reflexões e análises econômicas por parte da literatura aqui examinada. Em grande parte da América Latina, a crise da dívida externa gerou uma restrição de divisas severa e duradoura. A política econômica passou a ser orientada para a obtenção de superávits comerciais de forma a atender os compromissos externos. Isso foi feito com ajuste exportador e, principalmente, redução das importações, o que impôs a interrupção do crescimento. Além disso, a década de 1980 foi marcada por diversos desequilíbrios macroeconômicos, dos quais se destaca a aceleração inflacionária. Os resultados em termos de produto per capita e desigualdade social justificaram a denominação de "década perdida" e grande parte dos economistas latino-americanos se dedicou à compreensão do fenômeno inflacionário e de suas particularidades, assim como à elaboração de propostas de políticas de estabilização monetária.

Apesar dessa reorientação geral em direção aos problemas conjunturais e macroeconômicos que a região enfrentava, foram publicadas duas obras por Fernando Fajnzylber $(1983,1988)$ que serviriam de inspiração para a retomada da agenda de longo prazo pela CEPAL a partir da década seguinte. O documento institucional “Transformação produtiva com equidade" (TPE), lançado em 1990, retomou os principais elementos analíticos daquelas obras e, combinando elementos caros à tradição cepalina prebischiana, inaugura uma nova fase, referida como "neoestruturalista" (BIELSCHOWSKY, 2000, p. 60).

Nas obras originais de Fajnzylber, o vínculo estritamente econômico entre crescimento e equidade teria um duplo sentido. O crescimento, ao induzir aumentos de produtividade do trabalho, conduziria a melhorias nas remunerações e na equidade; ao mesmo tempo, esta última favoreceria o crescimento ao permitir a realização de bens de consumo cuja produção se expande. É nesse último sentido que Fajnzylber atribui um papel relevante ao mercado interno, em sintonia com o pensamento cepalino pré-1980.

No entanto, as melhorias do volume de emprego e das remunerações do trabalho não só configuram condições necessárias para realizar a produção e, por conseguinte, o próprio processo de acumulação e crescimento, como também devem trazer consigo melhorias na distribuição de renda (RODRÍGUEZ, 2009, p. 521).

Explica-se melhor esse ponto. Para Fajnzylber, maior equidade é uma variante ou uma especificação das condições de realização da produção (RODRÍGUEZ, 2006, p. 523). Mais do que sua implicação econômica, importa o sentido e o significado social ou psicossocial da equidade: o de integração das maiorias à "nova aliança”, condição essencial para lhe dar continuidade e força transformadora. Ou seja, a equidade fomenta o sentido de pertenci- 
mento à coletividade, possibilitando sua colaboração com um padrão de consumo mais austero e, supostamente, compatível com uma maior taxa de crescimento.

El sentido de pertenecer a una sociedad y de estar integrado a la colectividad estimula, en todos los estratos sociales, la buena disposición para participar en el esfuerzo colectivo que supone la postergación parcial del consumo en aras del crecimiento económico. La equidad favorece el crecimiento directamente al crear un patrón de consumo compatible con una tasa más alta y más eficiente de inversión e indirectamente al generar un clima social compatible con el esfuerzo de construcción a futuro. Esto exige legitimar la elite y el sistema para instar al conjunto de la sociedad a emprender las acciones y decisiones que llevan a cumplir ese objetivo. (FAJNZYLBER, 1990, p. 66)

Portanto, melhorias na equidade seriam favoráveis ao crescimento de duas formas: primeiro, servindo de mercado interno para a realização da produção; segundo, ao possibilitar, pelo lado da oferta de fundos, taxas maiores de acumulação. Essa última condição é contemplada por dois argumentos: um primeiro, sociológico, de que haveria maior disposição a um sacrifício em termos de consumo por parte da massa trabalhadora, quando esta se sente integrada e pertencente a uma "aliança social" (desenvolvido em FAJNZYLBER, 1990); e outro, econômico, de que o padrão de consumo mais equitativo envolveria a produção de bens de consumo com uma relação capital/produto menos elevada (desenvolvido em FAJNZYLBER, 1992). Esse último argumento necessita de uma hipótese bastante particular, que merece ser desenvolvida com mais calma.

Assim como outros autores cepalinos, Fajnzylber parte de uma interpretação crítica à forma que assumiu a industrialização latino-americana, no sentido de que a concentração de renda teria sido acompanhada de um consumo imitativo comprometedor da poupança e, por essa via, da própria acumulação e do crescimento. Esse tipo de consumo teria sido baseado em bens duráveis, especialmente da indústria automotriz, com enormes exigências de energia cara e de obras de infraestrutura, tendo gerado muita demanda por importações e pouca aprendizagem interna (RODRÍGUEZ, 2009 , p. 527). Em sintonia com a abordagem dos "estilos de desenvolvimento" dos anos 1970, Fajnzylber preconiza que seria possível, do ponto de vista normativo, outra forma de associação entre aquelas variáveis (distribuição e acumulação de capital), de forma a resultar numa relação sinérgica, ao invés de inibidora.

Para tanto, Fajnzylber assume a hipótese de que as melhorias na equidade dão lugar à formação de padrões de consumo delimitados pela austeridade e, devido à sua composição, poderiam influir favoravelmente na relação capital-produto e dinamizar a economia (BIELSCHOWSKY, 2000, p. 61; RODRÍGUEZ, 2009, p. 527). 
A equidade e aquilo que representa em termos de articulação social, a igualdade do nível médio de renda, tendem a configurar um padrão de consumo relativamente mais austero que o prevalecente em situações de aguda concentração de renda, na medida em que inibe os setores de maiores rendas de reproduzir em grau caricatural um padrão de consumo proveniente das sociedades mais avançadas.

Adicionalmente ao fato de que um padrão de consumo mais austero libera recursos para o investimento, poder-se-ia adiantar a hipótese de que existiria uma certa relação entre o grau de exuberância do "padrão de consumo" e o nível da relação capital-produto; este seria mais baixo naquelas sociedades cujo padrão de consumo seria mais austero, medido este por uma menor proporção de consumo durável, menor uso de energia e menor uso de divisas. (FAJNZYLBER, 1992, p. 9)

Para Serrano (2001), essa construção teórica presente da obra de Fajnzylber reflete as dificuldades de se conciliar a defesa da equidade social e o crescimento quando se parte de uma abordagem teórica baseada na determinação clássica do investimento e na Lei de Say. Dentro da lógica clássica, os citados objetivos seriam, a princípio, contraditórios: como a propensão a consumir dos trabalhadores é maior do que a dos capitalistas, uma redistribuição de renda geraria um efeito líquido de redução da poupança agregada e, em consequência, uma redução no investimento. Fajnzylber, então, "resolve" esse dilema assumindo uma "hipótese arbitrária", nas palavras de Serrano, de que o padrão de consumo dos trabalhadores seria diferente daquele dos capitalistas, no sentido de que as tecnologias produtoras dos bens consumidos pelos primeiros seriam menos intensivas em capital, energia e recursos escassos. Essa suposição permitiria ao autor assumir que a relação capital-produto após a redistribuição seria menor e que, portanto, seria possível compatibilizar parcela menor dos lucros (e da poupança-investimento) no produto com crescimento idêntico (ou maior) da capacidade produtiva (SERRANO, 2001, p. 141-142).

Fajnzylber considera que essa forma positiva de associação entre melhor distribuição de renda e acumulação não é um resultado necessário e espontâneo, mas dependeria de políticas econômicas e de mecanismos institucionais que assegurassem, por um lado, a austeridade por parte das grandes massas e, por outro, o comportamento esperado dos agentes investidores.

Nesse sentido, apesar de fazer referência ao papel do mercado interno na realização da produção, a obra de Fajnzylber concede maior importância ao esforço de austeridade e à intensidade de capital da estrutura produtiva como determinantes do crescimento econômico. Portanto, sua obra pode ser apreendida como um retorno ao paradigma clássico/ricardiano da teoria do investimento que marcou as primeiras 
décadas do Estruturalismo cepalino, pois não incorporou os avanços analíticos introduzidos na década de 1970 sobre a determinação do crescimento pela demanda. O mercado interno fica, afinal, relegado a um papel secundário.

A década de 1990 observou uma importante inflexão do contexto econômico e sociopolítico na América Latina, com a ampla adesão às reformas liberalizantes (abertura comercial e financeira, privatização e flexibilização laboral, entre outras), que compuseram o chamado "Consenso de Washington". Ademais, disseminava-se pela região uma redefinição da estratégia de intervenção estatal em novos marcos regulatórios, em oposição ao papel mais ativo do Estado que marcara o pensamento e a prática “desenvolvimentistas" nas décadas anteriores.

A renovação "neoestruturalista" da agenda cepalina dos anos 1990 propôs, nesse ambiente e com essas restrições, a centralidade do problema da desigualdade social cujas grandes dívidas históricas se agravaram no contexto recessivo e inflacionário dos anos 1980, assim como não foram atenuadas pelo período de reformas e choques de produtividade da estrutura produtiva na década em questão. Afinal, apesar da melhora da situação econômica, a partir da reversão do estrangulamento externo e dos logros com a estabilização de preços, os anos 1990 foram marcados por efeitos perversos do progresso técnico e do baixo crescimento sobre o emprego formal e a desigualdade.

Houve o avanço de uma arquitetura conceitual baseada na cidadania, coesão social e direitos (inclusive incorporando o marco ético dos direitos humanos das Nações Unidas). A relação da equidade com o crescimento, contudo, passou a ser definida principalmente por seus atributos sociopolíticos (referentes à estabilidade exigida pelo crescimento) e pelo lado da oferta. As políticas de promoção da equidade incluiriam investimento em capital humano e transferências. As últimas, contudo, seriam obtidas à custa do crescimento econômico, pois, por se constituírem gastos correntes, reduziriam a poupança agregada. Por isso, deveriam ter um caráter mais focalizado. O investimento em capital humano, por sua vez, poderia significar, no máximo, um sacrifício do crescimento presente em prol de maior crescimento no futuro (CEPAL, 1992).

Apesar da proferida defesa da equidade como valor do desenvolvimento, a agenda neoestruturalista pouco avançou no tratamento econômico dessa dimensão (e, nesse sentido, se mostra aquém dos progressos obtidos na década anterior, na perspectiva aqui adotada).

\section{RUMO A UMA ABORDAGEM INTEGRADA: "CRESCER PARA IGUALAR E IGUALAR PARA CRESCER" (ANOS 2010)}

A primeira década do século XXI foi marcada pelo dinamismo do comércio internacional puxado pela economia chinesa. Para os países da América Latina, isso signifi- 
cou forte ampliação das exportações de commodities, em muitos casos a melhora nos termos de troca e o afastamento da restrição externa ao seu crescimento, completando a fase expansiva mais longa desde a década de 1970. Paralelamente, houve melhora nos indicadores de pobreza e de distribuição de renda. Essa experiência, por configurar uma importante novidade na história da América Latina, suscitou um renovado esforço de interpretação e, em alguns casos, interessantes reformulações/atualizações analíticas. No âmbito da CEPAL, um conjunto de documentos produzidos entre 2010 e 2014 configurou a chamada "Trilogia da Igualdade", posteriormente expandida para um conjunto de cinco documentos ${ }^{3}$ que delineiam os contornos da nova orientação normativa da instituição.

Nesses documentos, reafirma-se a necessidade de incorporar o valor de "igualdade" como princípio ético, normativo e objetivo último do desenvolvimento (CEPAL, 2010). Por um lado, a inclusão social é tratada no sentido amplo, incluindo elementos que incrementam as capacidades humanas, igualam as oportunidades, geram coesão social e combatem a reprodução intergeracional da exclusão. Nesse aspecto, configura-se uma extensão dos enfoques desenvolvidos pela CEPAL desde 1990 e da própria agenda da TPE. ${ }^{4}$ Contudo, em contraste com aquelas abordagens, o documento sinaliza mais diretamente a necessidade de fortalecimento do papel do Estado na redistribuição de renda e garantia de mecanismos de proteção social com clara vocação universalista, assim como no fortalecimento da institucionalidade no mercado laboral.

Outro elemento analítico introduzido, ainda que de forma preliminar, é a necessidade de pensar o desenvolvimento a partir da complementaridade entre o econômico e o social, o que configura um avanço em relação ao rumo geral das ideias dos anos 1990 .

Igualdade social e dinamismo econômico não estão em desacordo um com o outro e o grande desafio é encontrar as sinergias entre ambos. O que propomos vai nessa direção: é necessário crescer para igualar e igualar para crescer. No horizonte

3 Junto com a Trilogia (CEPAL, 2010, 2012a, 2014) somam-se duas publicações posteriores (CEPAL 2016a, 2016b).

4 Em termos da terminologia utilizada pelos documentos institucionais da CEPAL, segundo Bielschowsky e Torres (2018), os princípios fundamentais do conceito de "igualdade" já estariam presentes na forma que a CEPAL empregava o conceito de "equidade", pelo menos desde 2000. Nesses documentos, o termo equidade não tinha apenas o significado meritocrático ou simplesmente de igualdade de oportunidades, mas sim de igualdade de direitos: civis, políticos, sociais, culturais e inclusive os econômicos. A adoção do termo igualdade, a partir de 2010, traria, contudo, uma "explicitação mais contundente" dos valores expressos pela igualdade de direitos, no sentido do "pleno direito de cada um, pelo simples fato de ser parte da sociedade e independentemente dos seus logros individuais e recursos monetários, a ter acesso a certas coberturas de bem-estar social e reconhecimento" (CEPAL 2010, apud BIELSCHOWSKY e TORRES, 2018, p. 17-18). 
estratégico de longo prazo, igualdade, crescimento econômico e sustentabilidade ambiental têm que ir de mãos dadas. (CEPAL, 2010, p. 10, tradução nossa)

Em linha com esse raciocínio, a CEPAL propõe uma “visão integrada”, buscando compreender como extrair as potenciais sinergias entre as quatro dimensões do desenvolvimento: macroeconômica, produtiva, ambiental e social/trabalhista. ${ }^{5}$

Se, a princípio, a principal via para a inclusão social é o emprego de qualidade e bem remunerado, fruto da mudança estrutural, que tende a reduzir as brechas salariais e promover uma apropriação mais justa dos aumentos de produtividade, há, contudo, algumas ponderações a esse processo que culminam na atribuição de um papel central ao Estado. Para além de automatismos, a instituição reconhece que, "no mundo do trabalho, os aspectos institucionais são fundamentais para traduzir os aumentos de produtividade em melhoras distributivas e de qualidade do emprego" (CEPAL, 2012b, p. 67-68). Por isso, o Estado deve também zelar por uma institucionalidade laboral e regulamentações jurídicas que propiciem a apropriação mais justa dos ganhos de produtividade entre os atores da produção, como, por exemplo, a sindicalização e a negociação coletiva.

Ademais, em países em desenvolvimento, a grande segmentação do mercado de trabalho e o tamanho da informalidade exigem que, principalmente no curto e médio prazo, o Estado se aproprie de uma proporção dos incrementos de produtividade para financiar sistemas robustos e não contributivos de proteção social. Além disso, as transferências de renda têm importante papel ecônomo na sustentação da demanda agregada (CEPAL, 2012a, p. 242-243). Importante notar que, aqui, diferentemente dos documentos cepalinos da década de 1990, não há referência às transferências de renda como comprometedoras do crescimento de longo prazo.

Em suma, na nova agenda da CEPAL nos anos 2010, o potencial do mercado interno como fonte de crescimento e de mudança estrutural é resgatado (ainda que de forma pouco enfática). Com base em algumas passagens, percebe-se uma transição para a visão em que a dimensão social tem potencial de afetar positivamente o dinamismo econômico, pois, além de permitir elevar a produtividade média mediante capacitação e educação, "mantém os necessários níveis de demanda interna para reativar a atividade econômica" (CEPAL, 2012b, p. 10). Ademais, reconhece que há vários modos possíveis de combinar as quatro dimensões do desenvolvimento (produtiva, macroeconômica, ambiental e social), com distintos potenciais de sinergias entre elas, e que não há garantias de que o modelo vigente seja necessariamente aquele determi-

\footnotetext{
5 Esses aspectos são desdobrados com maior clareza em CEPAL (2012a).
} 
nado por um horizonte ético e normativo. O Estado, portanto, assume papel central na orientação da economia para um modelo de desenvolvimento dinâmico, inclusivo, sustentado (do ponto de vista da oferta) e ambientalmente sustentável.

No debate econômico brasileiro, a tradição estruturalista tem se desdobrado, ao longo da última década, em duas abordagens teóricas "desenvolvimentistas", que ganharam espaço com a estabilidade macroeconômica vigente desde meados da primeira década dos anos 2000 e os novos rumos insinuados durante os governos Lula e Dilma.

De um lado, autores do chamado "Novo Desenvolvimentismo", especialmente preocupados com o processo de "desindustrialização" da economia brasileira, criticam o crescimento com poupança externa e a apreciação da taxa de câmbio e concentram suas proposições em medidas de política macroeconômica. Essas últimas podem ser sintetizadas na "correção" de cinco preços macroeconômicos: taxa de câmbio, taxa de juros, taxa de salários, taxa de lucros e taxa de inflação. Grande ênfase é concedida à taxa de câmbio, que teria "um papel decisivo no desenvolvimento econômico porque ela é como um interruptor que liga ou desliga as empresas competentes do país tanto do mercado externo quanto do mercado interno" (BRESSER-PEREIRA, 2014, p. 32).

A melhoria das condições de vida da população seria fruto do próprio desenvolvimento industrial que, ao elevar a produtividade média, permitiria o crescimento dos salários reais sem pressionar o custo unitário do trabalho e os lucros das empresas, mantendo estável a distribuição funcional da renda (OREIRO, 2012, p. 33). Tal estabilidade é importante: o aumento cumulativo da participação dos salários na renda seria “inviável”, pois tenderia a gerar queda da taxa de lucro (que, a partir de certo nível, interrompe o investimento privado) e também uma tendência à apreciação da taxa real de câmbio.

Defende-se a superioridade da estratégia de crescimento do tipo export-led, tendo como referência o seu sucesso nos países industrializados da Ásia, ainda que isso implique, no caso do Brasil, na busca de competitividade baseada em salários nominais mais baixos e moeda nacional desvalorizada. A resultante compressão dos salários reais seria um custo necessário e temporário nesse processo.

Assim, a agenda novo-desenvolvimentista subordina a dimensão social à do crescimento e da estrutura produtiva. O mercado interno não é a principal fonte de dinamismo e o progresso social, embora seja reconhecidamente um valor importante, é condicionado à evolução da produtividade do trabalho. Numa estratégia do tipo export-led, os salários são vistos predominantemente como custo - que, ao lado do câmbio, afeta decisivamente competitividade - e menos como fonte de demanda e mercado consumidor.

De outro lado, a agenda "social-desenvolvimentista", como o nome sugere, coloca a questão social no centro das preocupações, em suas várias dimensões: relacionada à 
cidadania (direito à educação, saúde, transporte, infraestrutura urbana, habitação, previdência, assistência social, etc.) e à dimensão econômica (geração de empregos de qualidade, distribuição de renda, mercado interno como frente de expansão e o potencial econômico da agenda de direitos sociais). No primeiro sentido, incorpora parte da agenda proposta pela CEPAL desde os anos 1990, com relação ao tratamento da questão social em seu aspecto integral (incorporando extensivamente um conjunto de temas e valores) e normativo. O segundo sentido representa um esforço de integração das dimensões econômica e social, destacando potenciais sinergias.

A ampliação do consumo de massas, fundada na redistribuição funcional da renda (com ampliação dos rendimentos do trabalho acima da produtividade) e na ampliação do crédito, seria o fator primordial do crescimento (CARNEIRO, 2012).

Ademais, os avanços nos direitos sociais, a princípio intrinsecamente relacionados ao bem-estar coletivo e ao sentido civilizatório e moral do desenvolvimento, também possuem um grande potencial econômico. Investimentos em infraestrutura social, nas áreas de educação, saúde, transporte etc., têm efeitos multiplicadores importantes em termos de emprego, renda e dinamização da economia. Ademais, têm o efeito de deslocar uma parcela da renda das famílias, antes comprometida com esses serviços, para outros usos, aquecendo a demanda no mercado privado de bens e serviços. Esse impacto é tão mais importante quanto mais pobre for o segmento da população. Assim, a ampliação da renda disponível por meio dos serviços públicos parece ser um instrumento poderoso de avanço na distribuição da renda (BIANCARELLI, 2013, p. 49). ${ }^{6}$

Em contraponto com a visão novo-desenvolvimentista, faz-se alusão à importância da área fiscal, inclusive das despesas correntes, sendo grande parte delas compostas por gastos sociais, como fonte de construção de uma sociedade mais justa e com maior potencial de crescimento (BIANCARELLI, 2013, p. 49).

Bielschowsky (2014) contribui com essa construção teórico-analítica, embora se voltando mais especificamente à viabilidade do desenvolvimento da economia brasi-

6 Rossi et al. (2018) partilham do princípio básico da visão social-desenvolvimentista, na medida em que consideram a distribuição de renda (e a resultante ampliação do mercado interno) como um "motor" do crescimento econômico. Contudo, introduzem duas contribuições a essa agenda. Primeiramente, dão centralidade ao investimento social como um segundo "motor" do crescimento, portador de grande potencial dinâmico tanto no curto como no longo prazo devido às grandes carências existentes no país. Em segundo lugar, consideram que esses dois "motores" também deveriam orientar a diversificação do setor produtivo e a oferta de empregos de qualidade. Ou seja, as demandas sociais deveriam servir como princípio orientador e legitimador das políticas produtivas e tecnológicas, criticando os objetivos industrializantes típicos de qualquer desenvolvimentismo. Em suma, os autores avançam na descrição normativa de um tipo de desenvolvimento que utilize os anseios sociais como as fontes orientadoras tanto para o crescimento como para a direção e composição da mudança estrutural. 
leira no contexto do século XXI, ao propor um "desenho conceitual” baseado em "três frentes de expansão": (i) demanda nacional e mundial pelos recursos naturais brasileiros; (ii) amplo mercado interno de consumo de massa; e (iii) demanda estatal e privada por investimentos em infraestrutura (econômica e social). As duas últimas estão relacionadas à dimensão distributiva e social. As palavras do autor alinham o raciocínio à tradição aqui tratada:

(...) trata-se de um enfoque ao mesmo tempo keynesiano, kaldoriano e estruturalista. Inspira-se em Keynes (1982) porque toma o investimento como resultado de estímulos de demanda efetiva; em Kaldor (1989), porque considera o progresso técnico e o learning by doing processos que acompanham o investimento gerado por expansão de demanda e ajudam a alimentar os rendimentos crescentes de escala que permitem o aumento de produtividade. É estruturalista porque, ao centrar a análise no investimento e nas transformações estruturais que suscita, orienta a discussão diretamente ao "estilo" de desenvolvimento desejado e historicamente viável (Pinto, 1976). (BIELSCHOWSKY, 2014, p. 117)

O Social-Desenvolvimentismo reconhece que a articulação da distribuição de renda com o crescimento não é suficiente para o desenvolvimento virtuoso. Os avanços sociais e o próprio crescimento dificilmente serão sustentados sem que haja indústria forte, competitiva e inovativa. Paralelamente ao desenvolvimento do mercado de consumo de massas, faz-se necessário que essa demanda interna seja acompanhada por uma correspondente expansão da produção doméstica. Porém, a agenda social-desenvolvimentista apresentada em CGEE (2013) não avança nesse sentido, indicando o enorme campo de investigação e pesquisa adicionais. Nesse sentido, evidencia-se sua estrutura atual mais como uma agenda do que efetivamente como um corpo teórico bem definido.

Por fim, destaca-se a proximidade entre os posicionamentos teóricos do social-desenvolvimentismo e da "abordagem integrada" da CEPAL, que podem ser sintetizados em quatro elementos principais: (i) incorporação do valor da igualdade (ou melhoria na distribuição de renda) a um enfoque integrado entre duas ou mais dimensões ("estilos de desenvolvimento"); (ii) a igualdade, intermediada pelo mercado interno, como motor do crescimento e eixo do desenvolvimento; (iii) o papel do Estado e das políticas públicas na configuração do estilo de desenvolvimento desejado; e (iv) o reconhecimento de que ausência de mudança estrutural pode se configurar num limite ao crescimento inclusivo. 


\section{CONSIDERAÇÕES FINAIS}

Este artigo buscou analisar a literatura estruturalista latino-americana, que sempre teve como importante referência os economistas ligados à CEPAL. Partindo de desdobramentos históricos observados na região, essa tradição foi marcada por controvérsias e contribuições envolvendo a articulação entre estrutura produtiva, crescimento e distribuição de renda, que podem fornecer importantes lições para a discussão sobre teoria do desenvolvimento nos dias atuais.

A obra original de Prebisch inaugura a trajetória aqui acompanhada, tendo representado um distanciamento da teoria do desenvolvimento elaborada nos países centrais que via a condição do "atraso" como uma etapa do processo de desenvolvimento observado no centro e adotava certo otimismo sobre a sua superação). Prebisch e Furtado caracterizaram a condição dos países latino-americanos como um processo autônomo, cuja estrutura e lógica de funcionamento diferiam essencialmente dos vigentes nas economias centrais.

Para além da rica caracterização do subdesenvolvimento, Furtado avançou para uma hipótese mais radical, que previu a tendência dessas economias à estagnação caso não fossem adotadas reformas de base. A passagem da história mostrou que o enfrentamento das causas do subdesenvolvimento (a heterogeneidade estrutural, envolvendo a concentração fundiária e da renda) não foi estritamente necessário para a manutenção das condições de acumulação e crescimento e mesmo para a continuidade do desenvolvimento de estruturas produtivas (por exemplo, de novos segmentos de bens de consumo duráveis). Tavares e Serra, nos anos 1970, atestaram que os gastos autônomos e a própria concentração de renda foram determinantes para puxar o crescimento econômico e a passagem para uma nova etapa do processo de industrialização, ainda que dentro dos moldes do subdesenvolvimento.

Do ponto de vista teórico, a contribuição de Tavares e Serra representou a adoção do paradigma keynesiano/kaleckiano, segundo o qual o princípio da demanda efetiva é determinante para as condições de acumulação. A demanda, por sua vez, é determinada apenas em parte pelo padrão distributivo, sendo crucial o papel desempenhado pelos gastos autônomos - ou seja, aqueles que não dependem diretamente da renda corrente, como, por exemplo, o crédito ao consumo.

Especificamente naquele "momento" da história do pensamento estruturalista latino-americano (o segundo, na divisão aqui proposta), é preciso atentar para a dissociação implícita entre duas problemáticas. De um lado, a acumulação, que inclui a análise positiva das condições de realização dinâmica daquele sistema econômico. Ou seja, a análise das fontes de demanda efetiva que puxarão as decisões de gasto privado na economia e a passagem por ciclos econômicos. De outro, há a questão dos "estilos" 
de desenvolvimento, que trata da articulação do crescimento com as estruturas produtivas e com a base social, considerando determinado molde normativo (podendo incluir a diminuição da desigualdade, preservação do meio ambiente, "adequação da tecnologia" às finalidades contidas no projeto nacional etc.).

A dissociação teórica e analítica entre essas duas problemáticas é essencial para entender como a (re)composição das condições necessárias à acumulação de capital não exige, necessariamente, a superação das condições que marcam o subdesenvolvimento.

Nos anos 1990, mediante o alargamento normativo sobre os horizontes sociais que devem compor o desenvolvimento econômico na região, o tema da equidade adquiriu importância. Contudo, a questão social se manteve relativamente separada da discussão do crescimento econômico e se conectava à questão estrutural sobretudo pela via da qualificação, educação e treinamento da mão de obra.

O quarto e último "momento" emergiu sobretudo no início dos anos 2010, após uma década de crescimento acelerado e experiências de avanços na inclusão social. As iniciativas teóricas que emergiram no Brasil e na nova agenda cepalina refletiram essa realidade. Além de figurar como um "valor" do desenvolvimento, a distribuição de renda foi apreciada e explorada em seu potencial de complementaridade e sinergia com a dimensão econômica do desenvolvimento.

Assim, esse último "momento" trouxe a necessidade de um enfoque integrado: embora se reconheça que as dimensões do crescimento econômico e da justiça social tenham, stricto sensu, determinantes relativamente autônomos, a incorporação de ambos os objetivos no mesmo corpo analítico é desejável no sentido da investigação do desenvolvimento.

Essa é, portanto, a oportunidade para reafirmar teses importantes do subdesenvolvimento relacionadas à heterogeneidade estrutural e à má distribuição de renda na região que marcaram o pensamento da CEPAL nas décadas de 1950 e 1960. A despeito dos retrocessos em curso no Brasil e na região - do ponto de vista intelectual e político - parece fundamental, para a reflexão estruturalista contemporânea, manter esse norte: uma agenda de desenvolvimento que priorize a inclusão social e o mercado interno, não estritamente como necessários para sustentar a acumulação capitalista, mas como eixos fundamentais de um "estilo de desenvolvimento" socialmente desejado e com potencial sinérgico com o próprio crescimento econômico e a mudança estrutural.

\section{REFERÊNCIAS}

BASTOS, C. P.; D’AVILA, J. G. O debate sobre o desenvolvimento na tradição heterodoxa brasileira. Revista Economia Contemporânea, v. 13, n. 2, p. 173-199, 2009. 
BIANCARELLI, A. "Recomendações para o avanço do pensamento social-desenvolvimentista". In: CGEE - CENTRO DE GESTÃO E ESTUDOS ESTRATÉGICOS. Desafios ao desenvolvimento brasileiro: uma abordagem social-desenvolvimentista. (Série Documentos Técnicos, n. 19, set. 2019) Brasília: CGEE, 2013, p. 45-66.

BIELSCHOVSKY, P. "Crescimento, distribuição de renda e progresso técnico: a controvérsia sobre os padrões de acumulação”. In: MALTA, M. M. (Org.). Ecos do desenvolvimento: uma história do pensamento econômico brasileiro. Rio de Janeiro: IPEA, 2011, p. 223-246.

BIELSCHOVSKY, R. "Estratégia de desenvolvimento e as três frentes de expansão no Brasil: um desenho conceitual". In: CALIXTRE, A. B.; BIANCARELLI, A. M.; CINTRA, M. A. M. (Orgs.). Presente e futuro do desenvolvimento brasileiro. Brasília: IPEA, 2014, p. 115-134.

BIELSCHOWSKY, R. (Org.) Cinquenta anos de pensamento na CEPAL. Rio de Janeiro: Record/ CEPAL, 2000.

BIELSCHOWSKY, R.; TORRES, M. Desarrollo e igualdad: el pensamiento de la CEPAL en su séptimo decenio. Textos seleccionados del período 2008-2018. Santiago de Chile: CEPAL, 2018.

BRESSER-PEREIRA, L. C. A construção política do Brasil. São Paulo: Editora 34, 2014.

CARNEIRO, R. M. Velhos e novos desenvolvimentismos. Economia e Sociedade, v. 21, Número Especial, p. 749-778, 2012.

CEPAL - COMISSÃO ECONÔMICA PARA A AMÉRICA LATINA E O CARIBE. Horizontes 2030: a igualdade no centro do desenvolvimento sustentável. Santiago de Chile: CEPAL, 2016a.

CEPAL - COMISSÃO ECONÔMICA PARA A AMÉRICA LATINA E O CARIBE. La matriz de la desigualdad social em America Latina. Reunión de la Mesa Directiva de la Conferencia Regional sobre Desarrollo Social de América Latina y el Caribe. Santo Domingo, 1 de noviembre de 2016. Santiago de Chile: CEPAL, 2016b.

CEPAL - COMISSÃO ECONÔMICA PARA A AMÉRICA LATINA E O CARIBE. Pactos para la igualdad: hacia un futuro sostenible. Trigésimo quinto período de sesiones de la CEPAL. Lima, 5 a 9 de mayo de 2014. Santiago de Chile: CEPAL, 2014.

CEPAL - COMISSÃO ECONÔMICA PARA A AMÉRICA LATINA E O CARIBE. Cambio estructural para la igualdad: una vision integrada del desarrollo. Trigésimo cuarto período de sesiones de la CEPAL. San Salvador, 27 a 31 de agosto de 2012. Santiago de Chile: CEPAL, 2012a.

CEPAL - COMISSÃO ECONÔMICA PARA A AMÉRICA LATINA E O CARIBE. Mudança estrutural para a igualdade: uma visão integrada do desenvolvimento. Santiago de Chile: CEPAL, 2012b.

CEPAL - COMISSÃO ECONÔMICA PARA A AMÉRICA LATINA E O CARIBE. La hora de la igualdad: brechas por cerrar, caminos por abrir. Trigésimo tercer período de sesiones de la CEPAL. Brasilia, 30 de mayo a 1 de junio de 2010. Santiago de Chile: CEPAL, 2010.

CEPAL - COMISSÃO ECONÔMICA PARA A AMÉRICA LATINA E O CARIBE. Equidad y transformación productiva: un enfoque integrado. Santiago de Chile: CEPAL, 1992.

CGEE - CENTRO DE GESTÃO E ESTUDOS ESTRATÉGICOS. Desafios ao desenvolvimento brasileiro: uma abordagem social-desenvolvimentista. Brasília: CGEE, 2013. 
FAJNZYLBER, F. Industrialização na América Latina: da "caixa negra” à "caixa postal vazia”. Revista de Economia Política, v. 12 (48), n. 4, 1992.

FAJNZYLBER, F. Industrialización en America Latina: de la "caja negra" al "casillero vacio": Comparación de patrones contemporáneos de industrialización. Cuadernos de La Cepal, Santiago de Chile, n. 60, 1990.

FAJNZYLBER, F. La industrialización en América Latina: de la "caja negra" al "casillero vacío". Revista Internacional de Ciencias Sociales, v. 40, n. 118, p. 495-502, 1988.

FAJNZYLBER, F. La Industrialización trunca de América Latina. México, DF.: Editorial Nueva Imagen, 1983.

FURTADO, C. Desenvolvimento e subdesenvolvimento. 2 ed. Rio de Janeiro: Fundo de Cultura, 1963.

FURTADO, C. Subdesenvolvimento e estagnação na América Latina. Rio de Janeiro: Civilização Brasileira, 1966.

KALDOR, N. "The role of increasing returns, technical progress and cumulative causation in the theory of international trade and economic growth in the United Kingdom". In: TARGETTI, F.; THIRLWALL, A. (Orgs.). The essential Kaldor. Inglaterra: Duckworth, 1989.

KEYNES, J. M. Teoria do emprego, do juro e da moeda. São Paulo: Editora Atlas, 1982.

LEWIS, A. Economic development with unlimited supplies of labour. The manchester School, v. 22, n. 2, p. 139-191, 1954.

MEDEIROS, C. A. “Desenvolvimento econômico, distribuição de renda e pobreza”. In: FIORI, J. L; MEDEIROS, C. A. de (Orgs.). Polarização mundial e crescimento. Petrópolis: Vozes, 2001.

OREIRO, J. L. Novo-desenvolvimentismo, crescimento econômico e regimes de política macroeconômica. Estudos Avançados, São Paulo, v. 26, n. 75, p. 29-40, maio/ago. 2012.

PINTO, A. "Notas sobre os estilos de desenvolvimento na América Latina”. In: BIELSCHOWSKY, R. (Org.). Cinqüenta anos de pensamento na CEPAL. Rio de Janeiro e São Paulo: Editora Record, 2000[1976], p. 609-650.

PINTO, A. Naturaleza e implicaciones de la "heterogeneidad estructural" de la América Latina. El Trimestre Económico, n.145, jan./mar. 1970.

PREBISCH, R. "Por uma dinâmica do desenvolvimento latino-americano". In: BIELSCHOWSKY, R. (Org.). Cinquenta anos de pensamento na CEPAL. Rio de Janeiro, São Paulo: Editora Record, 2000[1963], p. 451-494.

PREBISCH, R. O desenvolvimento econômico da América Latina e seus principais problemas. Revista Brasileira de Economia, v. 3, n. 3, p. 47-111, 1949.

RODRÍGUEZ, O. El estructuralismo latinoamericano. Rio de Janeiro: Civilização Brasileira, 2009.

ROSSI, P. et al. Desenvolvimento social e estrutura produtiva. Caderno de Debates - GT de Economia do Projeto Brasil Popular, São Paulo, mar. 2018. Disponível em: <http://brasildebate. com.br/wp-content/uploads/Caderno-de-Deabtes-3_ProjetoBrasilPopular-1.pdf $>$. Acesso em: 09 dez. 2019. 
RUGITSKY, F. Growth, distribution, and sectoral heterogeneity: reading the Kaleckians in Latin America. EconomiA, v. 17, p. 265-278, 2016.

SERRANO, F. "A acumulação e o gasto improdutivo na economia do desenvolvimento". In: FIORI, J. L.; MEDEIROS, C. A. de (Org.). Polarização Mundial e Crescimento. Petrópolis: Vozes, 2001, p. 135-164.

TAVARES, M. C. "Auge e declínio do processo de substituição de importações no Brasil". In: TAVARES, M. C. (Org.). Da substituição de importações ao capitalismo financeiro. Rio de Janeiro: Zahar Editores, 1972.

TAVARES, M. C.; SERRA, J. “Além da estagnação". In: TAVARES, M. C. (Org.). Da substituição de importações ao capitalismo financeiro: ensaios sobre a economia brasileira. Rio de Janeiro: Zahar Editores, 1972. 